\title{
Is Prescott right? Welfare state policies and the incentives to work, learn, and retire
}

\author{
Bas Jacobs
}

Published online: 30 September 2008

(C) The Author(s) 2008. This article is published with open access at Springerlink.com

\begin{abstract}
This paper bolsters Prescott's (Fed. Reserve Bank Minneap. Q. Rev. 28(1):2-13, 2004) claim that high taxes are responsible for lackluster labor market performance in Continental European countries. We develop a life-cycle model with endogenous skill formation, endogenous labor supply, and endogenous retirement. Labor taxation distorts not only labor supply, but also education and retirement decisions. Actuarially unfair pensions further exacerbate labor tax distortions on retirement. Education subsidies can nevertheless cushion the adverse impact of taxation on skill formation. Feedbacks between education, labor supply, and retirement are important. The model is simulated with realistic behavioral elasticities that are consistent with microeconometric evidence. If, besides labor supply, also learning and retirement are endogenous, the uncompensated (compensated) elasticity of the tax base equals $0.46(0.85)$, which is more than twice as large as the standard uncompensated (compensated) labor supply elasticity of 0.18 (0.40). Furthermore, life-cycle interactions between education, working, and retirement are quantitatively important and the interactions raise all behavioral elasticities substantially. For example, the uncompensated labor supply elasticity increases with one-half due to life-cycle interactions (to 0.26). We demonstrate that low European labor supply can be fully explained by taxation without relying on unrealistically high labor supply elasticities. Reducing labor market distortions, cutting benefit levels, lowering tax rates, and making (early) retirement actuarially more fair, therefore, boosts labor supply, delays retirement, and stimulates skill formation. In addition, high education subsidies are needed in large welfare states to offset explicit and implicit tax burdens on human capital investment.
\end{abstract}

B. Jacobs $(\bowtie)$

Erasmus School of Economics, Tinbergen Institute, Netspar and CESifo, Erasmus University Rotterdam, P.O. Box 1738, 3000 DR Rotterdam, The Netherlands

e-mail: bjacobs@few.eur.nl 
Keywords Skill formation · Human capital · Labor supply · Retirement · Tax policy $\cdot$ Benefit systems $\cdot$ Pension policy $\cdot$ Welfare state

JEL Classification $\mathrm{H} 2 \cdot \mathrm{H} 5 \cdot \mathrm{I} 2 \cdot \mathrm{I} 3 \cdot \mathrm{J} 2 \cdot \mathrm{J} 3$

\section{Introduction}

In his influential article, Prescott (2004) provoked a heated debate on whether the high levels of taxation, which are associated with large welfare states, are responsible for the poor European labor market performance. Alesina et al. (2005) responded and demonstrated that taxation can only explain the European experience with empirically implausibly large elasticities of labor supply. As an alternative explanation, they propose a "social multiplier" in leisure demand, which creates a culture of leisure in which Europeans do not wish to work so hard as Americans do. ${ }^{1}$ Until now, the debate is far from settled, and this paper sheds new light on the issue.

We argue that labor supply is not the only relevant choice margin. Indeed, education and retirement are crucial determinants of labor market entry and exit and, therefore, of the size of the tax base. Education and retirement are both affected by taxation. According to the Le Châtelier Principle, the elasticity of the tax base is expected to increase substantially when more than one margin is affected by income taxation (Diamond and Mirrlees 2002). Income taxation reduces investments in human capital if not all education expenditures are tax-deductible forgone labor earnings. Indeed, direct costs are around one-quarter of total monetary costs (Trostel 1993). ${ }^{2}$ The labor tax directly distorts retirement decisions because utility from retirement is not taxed, whereas continued work is. This direct impact of labor taxation on retirement is often neglected. Indeed, the retirement literature mainly focuses on the implicit marginal tax rate on additional years of work due to the presence of actuarially unfair (early) retirement incomes; see, for example, Gruber and Wise (1999). An exception is Duval (2004), who also studies the effects of the direct marginal tax on retirement.

Furthermore, education, labor supply, and retirement interact over the life cycle. Investments in human capital only pay off if human capital is utilized in the labor market. The utilization rate of human capital increases with labor force participation and hours worked and human capital is written off at (early) retirement. ${ }^{3}$

\footnotetext{
${ }^{1}$ Alesina et al. (2005) present anecdotal evidence in favor of their "social multiplier," but solid empirical evidence is lacking. This explanation is the polar opposite of theories that emphasize rivalry in consumption, which results in rat-races and status seeking; see, for example, Layard (2005) If true, Americans would work excessively hard, in comparison with Europeans. In any case, both approaches share a short distance between assumption and conclusion; the explanation for observed behavior (too much or too little leisure) is essentially assumed.

${ }^{2}$ Nonmonetary costs, such as effort, are probably important as well in view of the observed high financial returns to education, which are considerably larger than the risk-free rate (Bovenberg and Jacobs 2005). In theory, noninsurable risks and capital market failures can also explain these high returns. However, empirically neither capital market imperfections nor risk have sufficient explanatory power to justify the observed high returns we see in the data. See the discussion in Jacobs (2007).

${ }^{3}$ High levels of taxation, generous social benefits, and strong labor market regulations reduce labor force participation rates, hours worked, and employment (see, e.g., Nickell 1997; Blundell and MaCurdy 1999;
} 
Low labor force participation rates of older workers imply that the time-horizons over which investments in human capital are harvested are short, and the incentives to invest in human capital are weakened accordingly. Similarly, incentives to participate in the labor market, to supply labor, and to retire later improve with higher levels of education because better-educated workers forgo higher labor earnings.

The data also suggest that complementarities between investment in human capital (skill creation), labor force participation (skill utilization), and retirement (skill depreciation) are important. The differences in labor force participation rates between workers with lower secondary education and workers with a tertiary education are double digit numbers (15-30\% points). The mirror image is that unemployment rates fall by $2-6 \%$ points when skill levels increase from lower secondary to tertiary education (OECD 2005a). Labor force participation rates of older cohorts are also much higher when individuals have more initial education. The difference in labor force participation rates between older workers with less than upper-secondary and those with tertiary education is roughly $20-30 \%$ points (OECD 2006). Skilled workers retire much later than unskilled workers.

The main questions of this paper are therefore the following. How do taxes affect skill formation (education), labor supply and retirement over the life cycle? And what is the impact of education subsidies and actuarially unfair pensions? How important are the complementarities between skill formation, labor effort, and retirement for the overall impact of welfare state policies on economic incentives and overall welfare?

To answer these questions, this paper develops and simulates a stylized life-cycle model of education (skill formation), labor supply (skill utilization), and retirement (skill depreciation). Following the human capital approach, individuals invest in human capital during initial periods of their life cycle, until the marginal costs of investing more time and resources are equal to the marginal benefits in the form of higher future wages; see, for example, Becker (1964), and Mincer (1974). After finishing initial education, individuals enter the labor market and utilize their human capital by endogenously supplying labor. The labor supply decision is modeled in a standard, neoclassical fashion. Human capital fully depreciates as individuals retire. The novelty of our model is that the retirement decision is modeled in a parsimonious way as the discrete decision to exit the labor market completely. Individuals retire when the marginal utility benefits of retirement are equal to the marginal costs of retirement: forgone labor earnings during the last year working.

Our theoretical model thereby contributes to the existing retirement literature. Often, researchers model retirement as a corner solution of zero labor supply by forcing wage rates to decline after some specified age (e.g., due to health shocks), by introducing work-related costs that increase with age, or by employing taste shifters in the utility function, which raise the marginal utility from leisure over time; see, for example, Gustman and Steinmeier (2005), and the references in de Hek and van

Saez 2002; Lalive et al. 2006). Generous early retirement and pension schemes give strong incentives to older workers to retire many years before statutory retirement ages (Gruber and Wise 1999). 
Erp (2007). These modeling strategies have the disadvantage that the optimal retirement age is to an important extent imposed by the modeling choices of the analyst, rather than being derived from optimizing behavior. Similarly, we do not need discrete choices in the labor supply decision, where labor supply takes discrete positive values before retirement, and is zero at retirement (for example, Rust 1989; van der Klaauw and Wolpin 2005; Blau 2007). A discrete labor supply choice has the unattractive property of being exogenous over wide intervals before retirement. Furthermore, the life-cycle model developed in this paper avoids the analytical nontractability of a Stock and Wise (1990) retirement option model, which is extended with endogenous labor supply in, for example, French (2005).

We show theoretically that taxation distorts labor supply, educational investment, and retirement. Actuarially unfair pensions further exacerbate tax distortions on retirement. Hours worked and later retirement are complementary to initial education. Skill formation is therefore impaired when the returns to skill formation are low if not much labor is supplied and skill utilization rates are low, and if skill depreciation is quick as a result of (early) retirement. More skill creation also boosts skill utilization, and slows down skill depreciation because higher levels of human capital raise the opportunity costs of leisure and retirement. Consequently, education policy can be important to cushion the distortionary impact of taxes and actuarially unfair pensions.

The theoretical model is simulated to quantify the impact of labor market distortions, (early) retirement schemes, and education policies on incentives to learn, to work, and to retire. We demonstrate that taxation is much more distortionary if, besides labor supply, education, and retirement decisions are taken into consideration. In particular, the uncompensated elasticity of the tax base (0.46) is more than twice as large as the conventional uncompensated elasticity of labor supply (0.18). Further, the conventional uncompensated labor supply elasticity increases with almost $50 \%$ (from 0.18 to 0.26 ) due to interactions of labor supply with education and retirement. Elasticities of retirement and education also substantially increase due to interactions. Hence, feedbacks between skill formation, skill creation, and skill depreciation are quantitatively important. To properly measure the welfare costs of welfare states, we also computed the compensated elasticities. Again, the compensated elasticity of the tax base (0.85) is more than twice as high as the conventional compensated labor supply elasticity (0.40). Welfare state policies therefore create much larger distortions than commonly believed. Our simulations show that low European labor supply can be fully explained by high levels of taxation, without relying on unrealistically high labor supply elasticities as in Prescott (2004), and without resorting to a "social multiplier" in leisure as in Alesina et al. (2005). ${ }^{4}$

Education policy can mitigate the adverse consequences of taxes on skill formation. In particular, policies to foster human capital cannot be seen in isolation from labor market policies, tax and benefit systems, and pension schemes. Education subsidies do not only reduce the explicit tax burden on skill formation, but also the implicit

\footnotetext{
${ }^{4}$ Indeed, it is perhaps more appropriate to think of the labor supply decision in macroeconomic models as a measure for labor supply in a broad sense, which encompasses more dimensions than only hours worked, but, for example, also education, retirement, and the labor force participation decision.
} 
tax burden caused by low skill utilization (also resulting from high taxes) and quick skill depreciation (resulting from actuarially unfair pensions). Furthermore, actuarially unfair pensions severely exacerbate the preexisting labor tax distortions on retirement choices. Hence, from a policy perspective it is not sufficient to restrict attention to reducing the implicit tax on retirement alone, as the explicit tax rate stimulates early retirement as well. Reforms in labor markets, pension systems and tax-benefit systems may not only have direct beneficial effects on labor supply and retirement, but may also have important dynamic efficiency gains by indirectly lowering implicit tax wedges on skill formation.

The remainder of this paper is organized as follows. The next section develops a theory of skill formation, skill utilization, and skill depreciation. Section 3 quantitatively illustrates the importance of interactions between skill formation, labor markets, and pension schemes. Section 4 provides the policy conclusions.

\section{A theory of skill formation, skill utilization, and skill depreciation}

We develop a standard life-cycle model, which is augmented with human capital investment, endogenous labor supply, and endogenous retirement. Labor markets are perfectly competitive and frictionless. ${ }^{5}$ By simultaneously analyzing human capital investment, labor supply, and retirement decisions, the model allows us to spell out various complementarities over the life cycle.

We assume that a representative individual is born at time $t=0$ and has a life-span $T$, which is exogenously given. During the first stages of the life cycle, the individual invests $S$ years acquiring human capital while not working at all. The decision to enter the labor market after initial education is therefore made on the extensive margin. If the individual is in the labor force, the individual endogenously supplies labor. Thus, labor is supplied on the intensive (hours) margin. Retirement is modeled on the extensive margin as the decision to exit the labor market completely at age $R$. The life-time time constraint states that total years in school $S$, in the labor market $R-S$, and in retirement $T-R$ should equal the life span $T$ of the individual:

$$
T=S+(R-S)+(T-R) .
$$

At each date, the individual derives instantaneous utility from consumption $C_{t}$. Only when the individual is in the labor market $(S<t \leq R)$, he may also derive utility from leisure $\mathcal{L}_{t}$. The time constraint while working states that the fraction of time working $L_{t}$ plus the fraction of time consumed as leisure $\mathcal{L}_{t}$ should be equal to the total time endowment - which is normalized at unity-

$$
1=L_{t}+\mathcal{L}_{t}, \quad S<t \leq R
$$

\footnotetext{
${ }^{5}$ This is probably not the best description of the labor markets in Europe, but economic theory is still in its infancy when it comes to studying the joint determination of labor supply, human capital formation, and wages in noncompetitive labor markets. See Charlot and Decreuze (2007), and the references therein, for an example.
} 
In this representative agent setting, one can alternatively interpret $L_{t}$ as the employment rate, and $\mathcal{L}_{t}$ as the nonemployment rate. Individuals also derive utility from the years they are retired $T-R$, where $R$ denotes the retirement age.

Life-time utility of the individual is given by a time-separable function of instantaneous consumption and leisure felicities, and retirement utility

$$
\int_{0}^{T} U\left(C_{t}\right) \exp (-\rho t) \mathrm{d} t+\int_{S}^{R} V\left(\mathcal{L}_{t}\right) \exp (-\rho t) \mathrm{d} t+X(T-R),
$$

with $U^{\prime}\left(C_{t}\right)>0, U^{\prime \prime}\left(C_{t}\right)<0, V^{\prime}\left(\mathcal{L}_{t}\right)>0, V^{\prime \prime}\left(\mathcal{L}_{t}\right)<0, X^{\prime}(T-R)>0$, and $X^{\prime \prime}(T-R)<0 . \rho$ is the subjective rate of time preference.

This preference structure requires careful treatment of all relevant time constraints. Double counting should be avoided by setting leisure time $\mathcal{L}_{t}$ at zero when individuals are enrolled in education, or when individuals are retired, i.e., $\mathcal{L}_{t} \equiv 0$ for $t \leq S$ and $R<t \leq T$. The value of retirement leisure is governed by $X(T-R)$. Adding leisure utility of retirement through $V\left(\mathcal{L}_{t}\right)$ would count leisure benefits of retirement twice. The costs of forgone labor time are measured by forgone labor earnings, as individuals spend their complete time endowment on education at the beginning of the life-cycle. Adding disutility from education effort via $V\left(\mathcal{L}_{t}\right)$ would count the time costs of education twice. ${ }^{6}$

By assuming that time devoted to retirement or education is a different commodity than time enjoyed as leisure during working life, we can completely separate the labor supply decision on the intensive margin from the education and retirement decisions on the extensive margin. The major advantage of doing so is that we obtain a parsimonious description of the education and retirement decisions, and a smooth path for labor supply over the working career. However, the utility function is also partially endogenous, since the domain of the utility integral for leisure is determined by endogenous education and retirement decisions. Hence, if more time is invested in education or spent in retirement, time available in the labor market and time enjoyed as leisure diminish. ${ }^{7}$

The individual optimally decides the number of years $S$ in education. $W(S)$ is the production function of human capital. $W(S)$ features positive but diminishing marginal returns to additional initial schooling: $W^{\prime}(S)>0, W^{\prime \prime}(S)<0 . W(S)$ is assumed to be constant over time. Alternatively, $W(S)$ can be seen as the rental rate of human capital of type $S$. The costs of education are earnings forgone while not working, and constant direct costs $P$ per year of education. All costs and benefits of education are monetary; we ignore nonmonetary costs or benefits.

The individual starts his life with $A_{0}$ in financial assets, which are normalized to zero for convenience $\left(A_{0}=0\right)$. Borrowing on a perfect capital market at constant real interest rate $r$ is possible to finance the costs of living and the costs of education in the

\footnotetext{
${ }^{6}$ The separability between consumption and leisure in the utility function is needed to avoid discontinuities in the marginal utility of consumption, since the individual only consumes hours of leisure while being in active in the labor market, and $\mathcal{L}_{t}=0$ for $t \leq S$ and $R<t \leq T$.

${ }^{7}$ The partial endogeneity of the utility function could be regarded as a drawback on theoretical grounds. Nevertheless, other approaches to capture the retirement decision and labor supply jointly are subject to more severe theoretical problems, see the Introduction for a discussion.
} 
periods during which the individual is enrolled in initial education. The flow budget constraint of the individual who is still in school $(t \leq S)$ is therefore given by

$$
\dot{A}_{t}=r A_{t}-C_{t}-(1-\sigma) P, \quad 0 \leq t \leq S,
$$

where a dot denotes a time-derivative. Since $A_{0}=0$, and $C_{t}$ and $P$ are both positive, the individual accumulates debt in the first periods of his life. $\sigma$ is the subsidy rate on direct educational costs.

After graduation, the individual starts earning gross labor income $W(S) L_{t}$. The flow budget constraints after graduation until retirement $(S<t \leq R)$ state that the increase in financial assets should equal total interest income (which is negative while individuals repay debts) plus net labor income $(1-\tau) W(S) L_{t}$, minus consumption

$$
\dot{A}_{t}=r A_{t}+(1-\tau) W(S) L_{t}-C_{t}, \quad S<t \leq R,
$$

where $\tau$ is the labor income tax rate. We assume for simplicity's sake that interest income is untaxed.

During retirement $(R<t \leq T)$, the individual runs down his accumulated assets for consumption purposes:

$$
\dot{A}_{t}=r A_{t}+\left(1-\tau_{B}\right) B-C_{t}, \quad R<t \leq T,
$$

where $B$ is the constant retirement benefit, and $\tau_{B}$ denotes the rate at which retirement benefits are taxed. One should interpret the pension benefit $B$ as that part pension benefits that is actuarially completely nonneutral, since individuals only receive retirement benefits conditional upon full retirement. Any actuarially fair pension savings are covered by the voluntary saving decision. The individual has no bequest motive and ends his life with zero wealth: $A_{T}=0$.

Integration of the asset accumulation constrains, and imposing the initial and terminal conditions on financial wealth, gives the life-time budget constraint of the individual

$$
\begin{aligned}
& \int_{0}^{T} C_{t} \exp (-r t) \mathrm{d} t+\int_{0}^{S}(1-\sigma) P \exp (-r t) \mathrm{d} t \\
& \quad=\int_{S}^{R}(1-\tau) W(S) L_{t} \exp (-r t) \mathrm{d} t+\int_{R}^{T}\left(1-\tau_{B}\right) B \exp (-r t) \mathrm{d} t
\end{aligned}
$$

The individual maximizes life-time utility by choosing consumption, labor supply, education, and retirement subject to the household budget constraint and the time constraints. ${ }^{8}$ Using standard routines we obtain the Euler equation for consumption:

$$
\frac{\dot{C}_{t}}{C_{t}}=\theta_{t}(r-\rho), \quad 0 \leq t \leq T,
$$

\footnotetext{
${ }^{8}$ We assume that first-order conditions are necessary and sufficient. The latter condition is not necessarily fulfilled due to the feedbacks between labor supply, retirement, and human capital accumulation. Only sufficiently strong decreasing returns in schooling, and sufficiently concave leisure and retirement subutility functions ensure an interior solution. We assume that these conditions are met.
} 
where $\theta_{t} \equiv\left(-\frac{U^{\prime \prime}\left(C_{t}\right) C_{t}}{U^{\prime}\left(C_{t}\right)}\right)^{-1}$ is the intertemporal elasticity of substitution in consumption. Similarly, we find a Euler equation for leisure:

$$
\frac{\dot{\mathcal{L}}_{t}}{\mathcal{L}_{t}}=\varepsilon_{t}(r-\rho), \quad S<t \leq R,
$$

where $\varepsilon_{t} \equiv\left(-\frac{V^{\prime \prime}\left(\mathcal{L}_{t}\right) \mathcal{L}_{t}}{V^{\prime}\left(\mathcal{L}_{t}\right)}\right)^{-1}>0$ is the intertemporal elasticity of substitution in leisure demand. Leisure time increases over time as long as the interest rate is larger than the pure rate of time preference $(r>\rho)$.

The static labor supply equation is also standard, and given by

$$
\frac{V^{\prime}\left(\mathcal{L}_{t}\right)}{U^{\prime}\left(C_{t}\right)}=(1-\tau) W(S), \quad S<t \leq R .
$$

The marginal willingness to demand leisure time decreases with the net wage rate and increases with the level of taxation. The gross wage rate increases with skill level $S$. Hence, this equation gives the first complementarity. Better-skilled workers supply more labor if the substitution effect dominates the income effect in labor supply (which is the empirically plausible case, see also Blundell and MaCurdy 1999; and Evers et al. 2008). Indeed, if labor supply is interpreted as the labor force participation rate, higher wages can explain why higher-educated workers also have higher participation rates.

The optimal number of years in initial education follows from the first-order conditions for education and labor supply:

$\int_{S}^{R}(1-\tau) W^{\prime}(S) L_{t} \exp (-r(t-S)) \mathrm{d} t=(1-\tau) W(S)\left(L_{S}+\frac{1-L_{S}}{\epsilon_{S}}\right)+(1-\sigma) P$,

where $\epsilon_{S} \equiv \frac{V^{\prime}\left(\mathcal{L}_{S}\right) \mathcal{L}_{S}}{V\left(\mathcal{L}_{S}\right)}>0$ is the elasticity of the leisure subutility function at time $S$. This is the modified Mincer equation stating that the net present value of marginal returns to initial education (evaluated at the time $S$ ) should be equal to net marginal costs of an additional year of schooling. The latter comprise net forgone labor earnings and direct, subsidized expenditures. Years spent in initial education increase when the returns to human capital investments are larger. We again encounter the first complementarity that returns to education increase when individuals supply more labor during working-life ( $L_{t}$ larger). The second complementarity is that investments in human capital increase when the working life is longer, and individuals retire later ( $R$ larger). We have to note here that the returns at the end of the life cycle are heavily discounted, so that expanding the retirement age only has small effects when discount rates are substantial.

The term $L_{S}+\frac{1-L_{S}}{\epsilon_{S}}$ originates from the fact that more time spent on initial education lowers the time-span over which labor can be supplied or leisure can be consumed; see the utility function (3). $L_{S}$ is associated with the marginal loss of forgone labor earnings, and $\frac{1-L_{S}}{\epsilon_{S}}$ is associated with marginal forgone leisure time when individuals invest more time in initial education. In the absence of endogenous labor supply during working-life, $L_{S}=1$, and this term cancels out. The same is true if the subutility function over leisure $V\left(\mathcal{L}_{S}\right)$ is linear, i.e., when $\epsilon_{S}=1$. In that case, more 
time spent in initial education reduces the marginal value of working and leisure time during working life equally.

Labor taxation reduces investments in initial education as long as direct costs are positive $(P>0)$, and the subsidy rate is not equal to the tax rate $(\tau \neq \sigma)$. If the subsidy rate $\sigma$ equals the tax rate on labor $\tau$, taxation is neutral with respect to human capital investments because all costs and benefits of human capital formation are symmetrically affected by tax and subsidy rates. Labor taxation nevertheless reduces labor supply (if the substitution effect dominates), and also reduces the retirement age (again assuming dominant substitution effects). Hence, labor taxation indirectly discourages investments in initial education by lowering the utilization rate of human capital while working and shortening the payback period of investments in education.

Optimal retirement is given by

$$
\frac{X^{\prime}(T-R)}{U^{\prime}\left(C_{0}\right) \exp (-r R)}=(1-\tau) W(S)\left((1-\varrho) L_{R}+\frac{1-L_{R}}{\epsilon_{R}}\right),
$$

where $\epsilon_{R} \equiv \frac{V^{\prime}\left(\mathcal{L}_{R}\right) \mathcal{L}_{R}}{V\left(\mathcal{L}_{R}\right)}>0$, and $\varrho \equiv \frac{\left(1-\tau_{B}\right) B}{(1-\tau) W(S) L_{R}}$ denotes the net replacement rate of retirement income in terms of final earnings. $\varrho$ is the implicit tax rate on continued work due to nonactuarially fair pensions. The marginal willingness to pay for an additional year in retirement should be equal to the marginal costs of an extra year in retirement. The marginal benefit is the marginal rate of substitution between retirement utility and consumption at the date of retirement. The marginal costs are given by the value of the net forgone labor earnings in the last year on the labor market. $U^{\prime}\left(C_{0}\right)$ captures wealth effects in the retirement decision. Richer individuals have a lower marginal utility of income and retire earlier-ceteris paribus. The individual has stronger incentives to retire later if he has more initial education $S$, since more education raises labor earnings forgone during retirement. Note also that incentives to retire are weaker when individuals utilize their skills better by supplying more labor during working life (higher $L_{R}$ ). The second complementarity is again that betterskilled workers retire later when the income effect of higher skills are outweighed by the substitution effects of higher skills.

Again, there is a term $(1-\varrho) L_{R}+\frac{1-L_{R}}{\epsilon_{R}}$ representing the impact of retirement on the time-span over which individuals enjoy labor earnings and ordinary leisure; see the utility function $(3)$. $(1-\varrho) L_{R}$ corresponds with the marginal loss of forgone labor earnings, which are reduced one-for-one with the implicit tax on retirement due to actuarially unfair pensions. $\frac{1-L_{R}}{\epsilon_{S}}$ measures the marginal value of forgone leisure time when individuals retire earlier. In the absence of an endogenous leisure demand decision and actuarially fair pensions $\left(L_{R}=1\right.$ and $\left.\varrho=0\right)$, this term would vanish. Similarly, the last term cancels out if the leisure subutility function $V\left(\mathcal{L}_{R}\right)$ is linear $\left(\epsilon_{R}=1\right)$, and pensions are actuarially fair $(\varrho=0)$. Later retirement then augments the marginal value of working and leisure time equally.

The labor tax directly distorts retirement decisions because retirement utility is not taxed, whereas continued work is. This direct impact of labor taxation on retirement is not often discussed in the literature on retirement (e.g., Gruber and Wise 1999). Indeed, this literature mainly focuses on the implicit marginal tax rate on additional years of work, $\varrho$, due to the presence of actuarially unfair (early) retirement incomes. 
Note that as long as net retirement benefits are taxed at lower rates than labor earnings are $\left(\tau_{B}<\tau\right)$, the tax system also distorts the retirement decision as the actuarial fairness of retirement benefits diminishes due to this asymmetric tax treatment. The implicit tax $\varrho$ on continued work exacerbates the impact of the labor tax $\tau$ on the decision to exit the labor market.

\section{Simulations}

How important is the impact of endogenous skill formation and retirement on the overall elasticity of the tax base? How important are the life-cycle interactions between skill formation and labor market choices quantitatively? Furthermore, how do welfare state policies, such as education subsidies and actuarially nonneutral pensions, affect skill formation, skill utilization, and skill depreciation? This section presents simulations of the model with some stylized policy settings. The baseline version of the model is calibrated on empirically observed values of the endogenous variables and policies, while using empirically grounded estimates for the main elasticities.

For simulation purposes, we translate the previous continuous time model to a discrete time setting. Utility is specified as

$$
\sum_{t=0}^{T} \frac{\frac{C_{t}^{1-1 / \theta}}{1-1 / \theta}}{(1+\rho)^{t}}-\sum_{t=S}^{R} \frac{\gamma \frac{\left(1-\mathcal{L}_{t}\right)^{1+1 / \varepsilon}}{1+1 / \varepsilon}}{(1+\rho)^{t}}+\eta \frac{(T-R)^{1-1 / \beta}}{1-1 / \beta},
$$

$\theta, \delta, \beta, \varepsilon$, and $\eta$ are all positive parameters. $\theta$ is the intertemporal elasticity of substitution in consumption. $\varepsilon$ governs the inter-temporal wage elasticity of labor supply. $\gamma$ is a parameter for the preference for leisure. $\beta$ is related to the elasticity of retirement with respect to net final earnings. $\eta$ is a parameter denoting the preference for retirement.

The production function for human capital is

$$
W(S) \equiv A S^{\alpha}, \quad 0<\alpha<1, A>0 .
$$

$A$ denotes the productivity of time invested in human capital. $A$ may be interpreted as a measure for ability. We solve the model numerically, see the Appendix for more details on the simulation procedure.

Table 1 summarizes the main parameters of the model. The time-span is set at 75 years, hence $T=75$. We assume that individuals start their education at age 6 . Hence, individuals die at age 81. A pure rate of time preference of $\rho=0.02$ is chosen, which is fairly standard. The same is true for the real interest rate, which is set at $r=0.04$. After an extensive review of the scarce empirical literature, Trostel (1993) sets the elasticity of the human capital production function at $\alpha=0.6$. We use a slightly lower value of $\alpha=0.55$. The price of education $P$ is 10 (thousand euro) per year, such that direct costs of education are one quarter of total costs (see also Trostel 1993). At baseline values, the individual's gross labor earnings per year are 29 (thousand euro) on average during working life. 
Table 1 Parameterization simulation model

\begin{tabular}{lll}
\hline Parameter & Value & Source \\
\hline $\begin{array}{l}\text { Preferences and technologies } \\
\text { Intertemporal elasticity consumption }\end{array}$ & $\theta=2$ & \\
Pure rate of time preference & $\rho=0.02$ & Calibrated: labor supply elasticity 0.2 \\
Intertemporal elasticity labor & $\varepsilon=0.5$ & Standard value \\
Leisure preference & $\gamma=13$ & Blundell and MaCurdy (1999) \\
Elasticity of retirement & $\beta=0.99$ & Calibrated: labor supply 87\% \\
Retirement preference & $\eta=7$ & Duval (2004), Gruber and Wise (1999) \\
Elasticity human capital & $\alpha=0.55$ & Calibrated: retirement at age 60 \\
Productivity human capital & $A=10$ & Calibrated: 12 years education \\
Time horizon & $T=75$ & Life span 81 years, education at age 6 \\
Prices & & \\
Real interest rate & $r=0.04$ & Standard value \\
Price per year of education & $P=10$ & 1/4 of total costs (Trostel 1993) \\
Policy variables & & \\
Labor tax & & \\
Education subsidy & $\sigma=0.5$ & OECD average \\
Implicit tax retirement & & OECD average higher education \\
\hline
\end{tabular}

Based on dozens of empirical studies, the meta-analysis by Evers et al. (2008) suggests values for the uncompensated wage elasticity of labor supply of 0.1 for men and 0.5 for women. We assume that it is equal to 0.2 in the base-line simulation. If labor supply is interpreted as labor force participation, rather than hours worked, the value for the elasticity is probably too low, because the extensive margin is typically more elastic than the intensive margin (Saez 2002). The Appendix shows that the uncompensated wage elasticity of labor supply (at zero nonlabor income) equals $(1-1 / \theta)(1 / \theta+1 / \varepsilon)^{-1}$. The intertemporal substitution elasticity of consumption $\theta$ and the intertemporal substitution elasticity of leisure $\varepsilon$ thus jointly pin down the uncompensated labor supply elasticity. Blundell and MaCurdy's (1999) review suggests values of the intertemporal elasticity of leisure between 0.5 and 1 . Auerbach and Kotlikoff (1987) use a value of 0.8 . We have set the intertemporal elasticity of substitution at the lower bound of $\varepsilon=0.5$. Thus, in order to ensure that the uncompensated labor supply elasticity roughly equals 0.2 , we set the intertemporal elasticity of substitution in consumption at $\theta=2$, which is relatively high. Indeed, a value of $\theta=1$ is often used in real business-cycle models; see, e.g., Lucas (1990). $\theta=0.5$ is suggested by most empirical microeconomic research; see, for example, Attanasio and Weber (1995). However, a too low value of $\theta$ gives implausibly low labor supply elasticities. Indeed, a value of $\theta$ below unity even results in backward bending labor supply curves (see Appendix). By setting $\theta=2$ we obtain realistic labor supply behavior and, as a side-effect, avoid excessively large wealth effects in retirement. Since our analysis does not focus on intertemporal distortions in consumption due to, for example, capital income taxes, missing capital markets, or liquidity constraints; we do not 
expect to bias the simulation results by assuming $\theta=2$. With this parameterization, the compensated wage elasticity of labor supply is equal to $(1 / \theta+1 / \varepsilon)^{-1}=0.4$ at zero nonlabor income (see Appendix).

The retirement elasticity is set at $\beta=0.99$. The Frisch elasticity of retirement with respect to the implicit tax on retirement (i.e., while holding wealth constant) equals $-\beta(T-R) / R$. At a calibrated retirement age of $R=54$ (age 60) the Frisch elasticity of retirement with respect to the implicit tax is around -0.28 . The estimates in Gruber and Wise (1999), OECD (2004) and Duval (2004) imply that the uncompensated elasticity of labor force participation of older workers with respect to the implicit tax on retirement (including wealth and income effects) is approximately one-third. The Appendix contains extensive sensitivity analyses by simulating the model with a wide array of behavioral elasticities.

The baseline set of policy variables is $\tau=0.5, \sigma=0.75$, and $\varrho=0.3$. These values match unweighted averages for a sample of 16 Continental European and AngloSaxon countries (see Appendix). Total marginal tax wedges on labor income (including employer contributions and local taxes) are $51 \%$ for a single household without dependents which earns the average production wage (OECD 2007a). 79\% is the average of subsidies on higher education, which probably corresponds better to a marginal subsidy than the average subsidy on all levels of education (OECD 2007b). Gruber and Wise (1999), OECD (2004), and Duval (2004) show that the implicit tax on retirement amounts to around $30 \%$ for an older worker aged between 55-65, although there are substantial cross-country differences. ${ }^{9}$ The remaining parameters $(A, \gamma, \eta)$ are calibrated such that the individual is enrolled in education until age 18, he retires at age 60 , and spends $87 \%$ of his time endowment supplying labor after graduation.

Tax revenues are absorbed by the government to finance spending on public goods and are not rebated. ${ }^{10}$ In the base-line simulation, the share of noneducation, nonpension spending is $30 \%$ of the present value of life-time income. Note that not only standard income and substitution effects of tax, education, and pension policies will matter in the simulations. Indeed, the tax and subsidy instruments do also affect the education decision, which determines yearly labor earnings. Therefore, changes in the level of education also cause income and wealth effects through their impact on earnings, and thereby indirectly influence labor supply and retirement. Similarly, changes in the retirement age affect life-time wealth, which causes wealth effects on labor supply as well.

Figure 1 plots the simulated life-cycle labor supply patterns for changes in the labor tax rate, education subsidy, and the implicit tax on retirement. Each panel shows that individuals are enrolled in initial education for the first years of their lives, then labor is supplied during working life, and the final years of life are spent in retirement. The time path of labor supply during working lives is downward sloping over the life

\footnotetext{
${ }^{9}$ Gruber and Wise (1999) report the so-called "tax force" statistic, which corresponds to the sum of marginal tax wedges on retirement while working during ages 55-69. Dividing the "tax force" by 15 gives a yearly average marginal tax wedge on retirement during working ages 55-69. OECD (2004) computes marginal tax wedges on retirement which are around 20\% (40\%) on average for 55-59 (60-64) year old workers. Duval (2004, p. 33) calculates that average implicit tax rates in OECD countries are equal to $30 \%$.

${ }^{10}$ Implicitly, we assume public goods enter in a completely separable fashion in the utility function.
} 

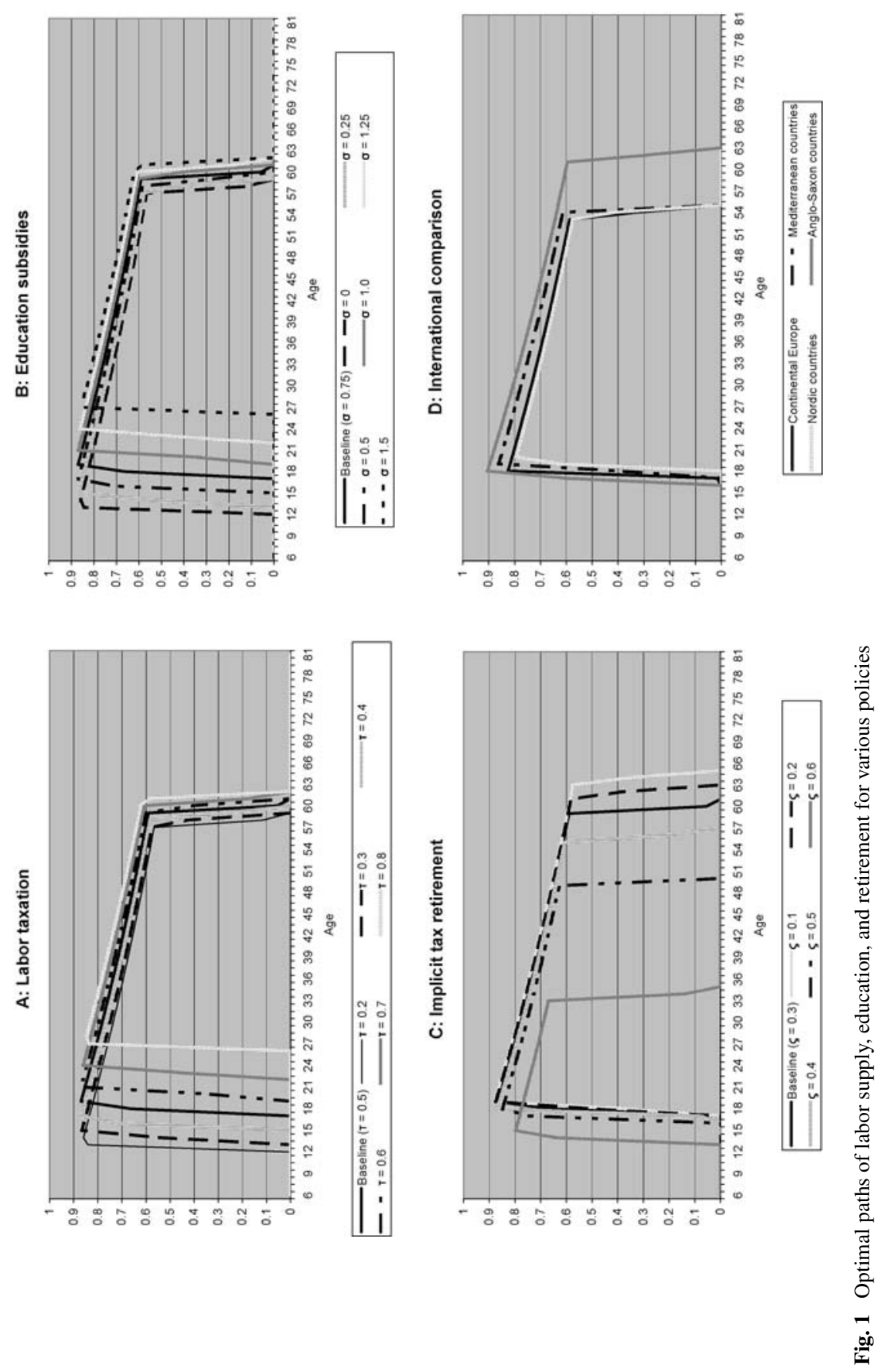
cycle as leisure rises over time, see the Euler equation for leisure (9). ${ }^{11}$ In the baseline simulation, labor supply at the end of the life cycle is around $60 \%$. If labor supply is interpreted as the employment rate, the downward sloping path matches falling labor force participation rates over the life cycle quite well (OECD 2006).

The simulations show that the policy environment is crucial to understand choices made over the life cycle. However, from these graphs alone we cannot infer to what extent these effects are driven by the direct impact of taxes on labor, education, and retirement or by their interactions. To disentangle the direct and interaction effects, we computed all (uncompensated and compensated) elasticities of labor supply, education, and retirement with respect to all the policy variables. The uncompensated elasticities are calculated by changing a policy variable and changing noneducation and nonpension spending to keep the public budget balanced. The compensated elasticities are computed by keeping life-time utility fixed at the baseline utility level with lump-sum transfers/taxes, which are financed by adjustments in noneducation and nonpension spending.

We calculated the elasticities that allow for the full effect of interactions between labor, education, and retirement, and the same elasticities where the interactions have been switched off. The latter is achieved by treating only one of the variables as endogenous, and by fixing the other two variables at the levels of the baseline simulation. Furthermore, we computed the uncompensated and compensated elasticities of the total tax base $(T B)$ for each policy instrument in all these cases. As a measure for the tax base, we take average yearly labor earnings over the entire life cycle. Hence, this measure for the tax base is sensitive to changes in labor force entry and exit. Table 2 shows the elasticities and reveals a number of important insights.

- Realistic elasticities - The first thing to note is that the calibration produces realistic values for the (un)compensated elasticities of education, labor, and retirement in the absence of interactions. With exogenous education and retirement, the uncompensated tax elasticity of labor supply is equal to 0.18 (in absolute value). Thus, our approximation to fix the wage elasticity at 0.2 has been reasonably accurate. Moreover, the approximation for the compensated wage elasticity of labor supply of 0.40 is exact. Furthermore, the uncompensated (compensated) retirement elasticity - at exogenous education and labor supply-with respect to the retirement wedge is $0.18(0.17)$ in absolute value, which is in the ballpark of empirical findings, albeit a bit on the low side. Not surprisingly, the uncompensated (compensated) education elasticity with respect to the subsidy is $0.48(0.48)$ —at exogenous labor and retirement - which matches the elasticity of the earnings function $(0.55)$ quite closely.

- Interactions important for tax elasticities - Panel A confirms that higher labor taxes result in rather large reductions in education, labor supply, and retirement ages. When besides labor supply, education, and retirement are also endogenous,

\footnotetext{
${ }^{11}$ There are small kinks in the labor supply paths, because the model is discrete, but the education and retirement choices are treated as continuous variables in the simulations. Therefore, the available timeendowment in a given year is adjusted so as to capture the nondiscreteness in education or retirement. For example, if an individual is enrolled for 12.2 years in education, the available time endowment in the 13 th year is adjusted to $1-0.2=0.8$. Similar adjustments are made for retirement.
} 


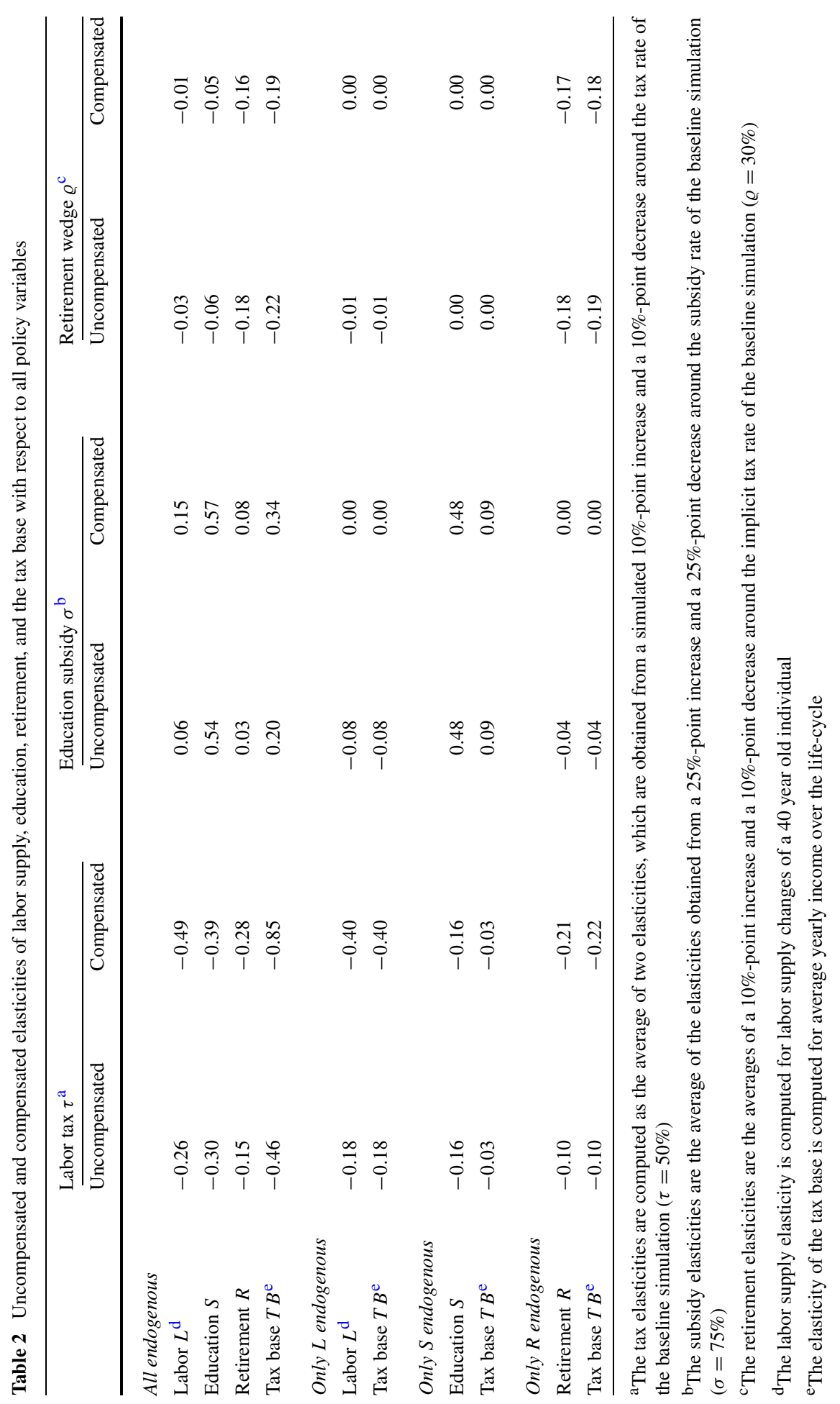


we see that the uncompensated labor supply elasticity with respect to the tax increases from 0.18 to 0.26 in absolute value. Consequently, interaction effects between labor supply, education, and retirement are important and drive up the tax elasticity of labor by almost 50\%. See also Jacobs (2005) and Bovenberg and Jacobs (2005). The education and retirement elasticities with respect to taxation are also substantially affected by interaction effects. The uncompensated education elasticity with respect to the tax rate almost doubles from 0.16 to 0.30 , whereas the retirement elasticity changes by $50 \%$ from 0.10 to 0.15 . All elasticities are taken in absolute values. Substitution effects dominate income effects in labor supply and retirement since we find negative uncompensated elasticities.

- Interactions not important for subsidy and implicit retirement tax elasticities - The subsidy on education only directly influences education choices. Similarly, the implicit tax on retirement only directly influences retirement. The cross-elasticities of education subsidies and retirement taxes are only driven by income effects, since the compensated cross-elasticities are zero. These findings illustrate that interaction effects are only important when one policy instrument affects multiple choice margins, as taxes do, but not when the policy instrument only affects one margin, such as subsidies and retirement benefits. This holds true for both uncompensated and compensated changes.

- Elasticity of the tax base corresponds directly with elasticities of labor supply or retirement when the other margins are fixed. This is not true for education-If education and retirement are fixed, the elasticity of the total tax base (with respect to any policy variable) is, not surprisingly, equal to the labor supply elasticity for both compensated and uncompensated changes. The same holds true for retirement, as long as education and labor are fixed. For education, this is different because it is an investment. A higher level of education partially erodes the tax base, since individuals reduce the length of their working career. Hence, the elasticities of the tax base are lower than that of education when labor supply and retirement are exogenous.

- Elasticity of the tax base with respect to the tax rate increases substantially due to interactions - The tax base is far more elastic when, besides labor supply, education and retirement are also endogenous. In particular, the absolute value of the uncompensated tax elasticity of the tax base rises from 0.18 - with only endogenous labor supply - to 0.46-with endogenous learning and retirement as well. This is a $150 \%$ increase. Therefore, the direct impact of taxes on education and retirement are also important, as can be witnessed from their uncompensated elasticities. This finding is the application of the Le Châtelier Principle (Diamond and Mirrlees 2002) because the elasticity of the tax base increases substantially when more than one decision margin is affected by income taxation. Moreover, all decisions mutually reinforce each other. Quite surprisingly, our findings of the uncompensated tax base elasticity are completely in line with the empirical estimate of 0.4 for the US by Saez and Gruber (2003).

- Elasticity of the tax base with respect to the subsidy rate increases substantially due to impacts on labor and retirement-The uncompensated subsidy elasticity of the tax base, including the interactions between labor, education, and retirement is 0.20 . This is more than twice as high as the tax base elasticity without the impact of 
education on labor and retirement (0.09). This is illustrated in Panel B. The subsidy only directly increases human capital investments, but does not directly affect labor supply and retirement. However, higher education subsidies indirectly boost labor supply and the retirement age as individuals become better educated. The costs of leisure and retirement increase with the level of human capital. Consequently, relatively strong effects on labor supply and retirement ages are found. Higher levels of education also result in higher incomes and larger life-time wealth, which raises the demand for leisure and stimulates earlier retirement. However, these income effects are outstripped by dominant substitution effects. Human capital policy can therefore be effective in offsetting the disincentives on skill formation created by taxation and actuarially unfair retirement schemes. Education subsidies help to contain the efficiency costs of redistribution by exempting skill formation from explicit and implicit taxes (cf. Bovenberg and Jacobs 2005).

- Elasticity of the tax base with respect to the implicit tax on retirement increases little due to impacts on education and retirement-The uncompensated elasticity of the tax base with respect to the implicit tax on retirement including the interactions between labor, education, and retirement is 0.22 . This is only slightly larger than the tax base elasticity without interactions with labor and retirement (0.19). See also panel C. This figure shows that human capital investments and retirement decisions interact only slightly because returns to education at the end of the life cycle are heavily discounted. Therefore, the feedback mechanism between education and retirement is asymmetric; more education boosts retirement more than later retirement boosts education. Labor supply responds marginally to a lower retirement wedge. Substitution effects in wages due to a higher education level are relatively small, and income and wealth effects - due to a longer working lifeare relatively large. Both effects roughly cancel out as indicated by a near-zero uncompensated elasticity of labor.

- Taxation much more distortionary than commonly understood-The compensated elasticities, which measure the efficiency losses of taxation are shown in the table as well. Again, we confirm that the compensated elasticities of labor, education, and retirement (with respect to any policy instrument) substantially rise due to the interaction effects. The impact is, however, more modest in comparison with the uncompensated elasticities. The reason is that the feedbacks between learning, working, and retirement are only driven by the uncompensated effects of taxes. Indeed, if the uncompensated labor supply elasticity were zero, labor supply would not change in response to a tax change, and there would be no interaction effects with learning and retirement. The same is true for retirement, but not for education; the reason being that compensated and uncompensated elasticities for education are always equal, since there are no income effects in education choices. Once education and retirement are allowed to be endogenous, we find a very high compensated elasticity of the tax base. In particular, the compensated elasticity of the tax base increases to 0.85 (an increase of more than $110 \%$ ) once education and retirement are allowed to be endogenous. The endogeneity of labor supply, education, and retirement can therefore be an alternative to the "social multiplier," which has been put forward by Alesina et al. (2005), to explain European labor market performance. 
Table 3 Policy packages for Continental European, Nordic, Mediterranean, and Anglo-Saxon countries

\begin{tabular}{llll}
\hline & $\tau$ & $\varrho$ & $\sigma$ \\
\hline Continental Europe (Netherlands, Belgium, France, Germany) & 0.60 & 0.40 & 0.83 \\
Mediterranean countries (Portugal, Spain, Italy, Greece) & 0.50 & 0.44 & 0.84 \\
Nordic countries (Denmark, Norway, Sweden, Finland) & 0.55 & 0.38 & 0.95 \\
Anglo-Saxon countries (UK, Canada, Australia, US) & 0.41 & 0.14 & 0.54 \\
\hline
\end{tabular}

Sources: Total marginal taxes on personal income, single worker without children earning $100 \%$ average production wage in 2006 (OECD 2007a). Education subsidies are computed as the proportion of public expenditure on educational institutions for tertiary education in 2004 (OECD 2007b). Implicit tax rates on retirement are the averages of for a 60-year old and 65-year old single worker with average earnings in 1999 (Duval 2004, p. 23)

Table 4 Observed data and simulated outcomes

\begin{tabular}{lllllll}
\hline & Observed $L_{40}$ & Simulated $L_{40}$ & Observed $S$ & Simulated $S$ & Observed $R$ & Simulated $R$ \\
\hline $\begin{array}{l}\text { Continental Europe } \\
\text { Mediterranean }\end{array}$ & 0.60 & 0.67 & 12.3 & 12.0 & 59.4 & 54.6 \\
$\quad$ & & & & & \\
$\quad$ countries & 0.72 & 0.70 & 9.8 & 12.5 & 62.2 & 55.0 \\
$\begin{array}{l}\text { Nordic countries } \\
\text { Anglo-Saxon }\end{array}$ & 0.64 & 0.65 & 13.0 & 13.2 & 62.4 & 54.7 \\
\hline
\end{tabular}

Sources: Hours worked are yearly average hours worked from OECD (2006). We have converted observed annual hours work in fractions of a total time endowment of 2,416 hours per year. This endowment is calculated by taking the Anglo-Saxon countries as the reference point and assuming that the simulated labor supply of a 40-year old worker equals the observed number of hours worked in the US. Data on average years of education in the population are taken from De la Fuente and Doménech (2006). Retirement ages are taken from OECD (2005b) and apply to males only

As a final exercise, we have simulated the model with a set of policy parameters that correspond with the policies of "Anglo-Saxon," "Continental European," "Mediterranean," and "Nordic" countries. Table 3 lists the policy packages for each block of countries, which are based on the (unweighed) averages of each group (see the Appendix for the underlying data). ${ }^{12}$

Panel D plots the simulated packages. These admittedly crude simulations show that only a few policy parameters are able to mimic observed life-cycle labor market behavior quite well. Table 4 confronts the simulated outcomes with the data. A caveat is in order here because the cross-sectional averages are not directly comparable to outcomes from our life-cycle model. The simulated results for education and retirement are not precise estimates for cross-sectional averages if these variables have not reached their steady-state values in the data. Certainly, this is the case for education and retirement. In most advanced countries, education levels have dramatically increased and retirement ages have fallen severely during the postwar period.

\footnotetext{
${ }^{12}$ Many countries have recently introduced reforms so as to make their pension systems actuarially more fair. The data on the implicit tax on retirement apply to 1999, and may therefore be slightly outdated.
} 
Bearing in mind the caveat, it is striking to find a very close correspondence between actual hours worked and simulated hours worked. Prescott's (2004) claim that Europeans work much less than Americans due to differences in tax levels can be fully explained by taxation alone. Neither education subsidies nor implicit taxes on retirement can explain this finding. Differences in the level of education subsidies would boost labor supply in Continental Europe compared to Anglo-Saxon countries. Hence, this explanation goes astray. Furthermore, implicit taxes on retirement hardly affect labor supply, as we have demonstrated earlier, see also Table 2. In contrast to Prescott (2004), our simulations are based on standard values for the labor supply elasticity; see also the discussion in Alesina et al. (2005).

Average educational attainment is highest in Nordic countries due to high education subsidies, and the simulated figure corresponds well with observed average years of education. Also, educational outcomes in Continental Europe match observed averages closely. The model does not predict average years of education in the US and Mediterranean countries well. Apart from cohort effects, this may be caused as well by substantial heterogeneity in education systems; we assume that education systems are identical across countries.

The simulations also substantially underestimate actual retirement ages in European countries, but is very accurate for the Anglo-Saxon countries. We do not think that the retirement elasticity is the culprit as it has been set at a relatively conservative value. The more probable explanation is the presence of cohort effects in the retirement data. Older cohorts had much less generous (early) retirement schemes than younger ones. Consequently, cross-sectional retirement data do not yet fully reflect the adverse incentive effects of (early) retirement schemes. Note that the total (implicit and explicit) tax wedges on retirement are $76 \%, 72 \%$, and $79 \%$ for Continental European, Mediterranean, and Nordic countries, respectively. Anglo-Saxon countries only have a total tax wedge on retirement of 55\%. Consequently, retirement decisions in Europe are extremely distorted, and small changes in taxes or retirement schemes result in substantial impact on the retirement age in our simulations. These model simulations vindicate the concerns of many policy makers who are reforming (early) retirement schemes. Moreover, it demonstrates the potential importance of the explicit tax on retirement choices.

A final remark is in order here. The simulated outcomes are as good as the model that produces them. The assumption of perfect clearing of the labor market can be criticized for being less relevant to the Continental European context. Higher marginal tax rates - for given average tax rates - typically reduce distortions in noncompetitive labor markets by punishing wage demands of unions, by lowering the power of efficiency-wages, or by reducing the bargaining power of workers in search models. However, higher average tax rates - for given tax progression-generally exacerbate labor market distortions by pushing the wage further above the market clearing level. See also Layard et al. (1991), Bovenberg and van der Ploeg (1994), Pissarides (1998), Sørensen (1999), Bovenberg (2006), and van der Ploeg (2006). Both mechanisms are clearly relevant for the Continental European countries, since they have both high marginal and high average tax burdens. Further, most of the above mentioned papers only analyze the extensive margin of labor supply, not the intensive margin. Thus, for those who are indeed in the labor market, the neoclassical labor 
supply model might still be the relevant one to describe labor supply behavior-even in Continental European countries.

\section{Conclusions}

This paper developed and simulated a life-cycle model with endogenous skill formation, endogenous labor supply, and endogenous retirement. We show that there are important feedbacks between education, labor supply, and retirement. Working more hours increases the utilization rate of acquired human capital. Later retirement implies that human capital depreciates less quickly. Moreover, skilled workers face weaker incentives to work less or retire early. Labor taxation not only distorts labor supply, but also education and retirement decisions. Actuarially unfair pensions exacerbate existing labor tax distortions on retirement. Education subsidies cushion the adverse impacts of taxation on learning, working, and retirement.

We simulated the life-cycle model with a realistic set of behavioral elasticities. Our simulations are able to mimic observed patterns of education, labor supply, and retirement quite well. In fact, our simulations bolster Prescott's (2004) claim that high taxes are responsible for lackluster labor market performance in Europe while not relying on implausibly high labor supply elasticities. We demonstrate that both compensated and uncompensated elasticities of the tax base are more than twice as high as standard labor supply elasticities. In particular, the uncompensated (compensated) elasticities of the aggregate tax base are as large as 0.46 (0.85). Furthermore, life-cycle interactions between learning, working, and retirement are quantitatively important and they raise all elasticities substantially. Welfare state policies therefore involve much larger distortions than is commonly perceived.

Reforms in labor markets, pension systems, and tax-benefit systems can thus have very substantial welfare gains. Indeed, if eligibility for various types of benefits and early-retirement schemes becomes more restricted, pension plans are made actuarially fairer, and distorting taxes are lowered, labor market performance improves directly. However, these policies also result in nontrivial efficiency gains because implicit tax wedges on skill formation are lowered, as the incentives improve to learn, to work, and to retire later. Moreover, higher investment in human capital boosts labor market performance, since better-skilled workers participate more and retire later. Human capital subsidies are consequently a vital part of modern welfare state policies to counter large direct and implicit taxes on skill formation arising from labor market distortions and actuarially unfair pension schemes.

Acknowledgements I am grateful to the Dutch Organization for Sciences for generous financial support (Vidi Grant No. 452-07-013, "Skill Formation in Distorted Labor Markets"). Part of this research was done when I was a visiting scholar at the Center for Economic Studies in München. I thank CES for providing support and their hospitality. I also wish to thank Lans Bovenberg and Ruud de Mooij and two anonymous referees for very useful comments and suggestions. 
Open Access This article is distributed under the terms of the Creative Commons Attribution Noncommercial License which permits any noncommercial use, distribution, and reproduction in any medium, provided the original author(s) and source are credited.

\section{Appendix}

Numerical solution

The Lagrangian for maximization of life-time utility is given by

$$
\begin{aligned}
\mathcal{V}= & \sum_{t=0}^{T} \frac{\frac{C_{t}^{1-1 / \theta}}{1-1 / \theta}}{(1+\rho)^{t}}-\sum_{t=S}^{R} \frac{\gamma \frac{L_{t}^{1+1 / \varepsilon}}{1+1 / \varepsilon}}{(1+\rho)^{t}}+\eta \frac{(T-R)^{1-1 / \beta}}{1-1 / \beta} \\
& +\lambda\left[\sum_{t=S}^{R} \frac{(1-\tau) A S^{\alpha} L_{t}}{(1+r)^{t}}+\sum_{t=R}^{T} \frac{\left(1-\tau_{B}\right) B}{(1+r)^{t}}-\sum_{t=0}^{T} \frac{C_{t}}{(1+r)^{t}}-\sum_{t=0}^{S} \frac{(1-\sigma) P}{(1+r)^{t}}\right] .
\end{aligned}
$$

First-order conditions for consumption, labor supply, education, and retirement are

$$
\begin{aligned}
& \frac{\partial \mathcal{V}}{\partial C_{t}}=\frac{C_{t}^{-1 / \theta}}{(1+\rho)^{t}}-\frac{\lambda}{(1+r)^{t}}=0 \\
& \frac{\partial \mathcal{V}}{\partial L_{t}}=-\frac{\gamma L_{t}^{1 / \varepsilon}}{(1+\rho)^{t}}+\frac{\lambda(1-\tau) A S^{\alpha}}{(1+r)^{t}}=0 \\
& \frac{\partial \mathcal{V}}{\partial S}=\frac{\gamma \frac{L_{S}^{1+1 / \varepsilon}}{1+1 / \varepsilon}}{(1+\rho)^{S}}-\frac{\lambda(1-\tau) A S^{\alpha} L_{S}}{(1+r)^{S}}+\lambda \sum_{t=S}^{R} \frac{(1-\tau) \alpha A S^{\alpha-1} L_{t}}{(1+r)^{t}}-\frac{\lambda(1-\sigma) P}{(1+r)^{S}}=0 \\
& \frac{\partial \mathcal{V}}{\partial R}=-\frac{\gamma \frac{L_{R}{ }^{1+1 / \varepsilon}}{1+1 / \varepsilon}}{(1+\rho)^{R}}-\eta(T-R)^{-1 / \beta}+\frac{\lambda(1-\tau) A S^{\alpha} L_{R}}{(1+r)^{R}}-\frac{\lambda\left(1-\tau_{B}\right) B}{(1+r)^{R}}=0
\end{aligned}
$$

The first equation yields the Euler equation for consumption:

$$
C_{t+1}=\left(\frac{1+r}{1+\rho}\right)^{\theta} C_{t} .
$$

Using the first two first-order conditions, we obtain the labor supply equation:

$$
L_{t}=\left(\frac{1}{\gamma}(1-\tau) A S^{\alpha} C_{t}^{-1 / \theta}\right)^{\varepsilon} .
$$

The education equation follows from rewriting the first term using the labor supply equation, $L_{S}^{\frac{1}{\varepsilon}}=\frac{1}{\gamma}(1-\tau) A S^{\alpha} C_{S}^{-1 / \theta}$, and the first-order condition for consumption, $C_{S}^{-1 / \theta}=\frac{\lambda(1+\rho)^{S}}{\left(1+r^{*}\right)^{S}}$ : 


$$
\begin{aligned}
\frac{\gamma \frac{L_{S}^{1+1 / \varepsilon}}{1+1 / \varepsilon}}{(1+\rho)^{S}} & =\frac{\frac{\gamma}{1+1 / \varepsilon}}{(1+\rho)^{S}} L_{S} L_{S}^{1 / \varepsilon} \\
& =\frac{C_{S}^{-1 / \theta}}{(1+\rho)^{S}} \frac{(1-\tau) A S^{\alpha} L_{S}}{1+1 / \varepsilon}=\frac{\lambda}{(1+r)^{S}} \frac{(1-\tau) A S^{\alpha} L_{S}}{1+1 / \varepsilon} .
\end{aligned}
$$

Substitution of the last result in the first-order condition for education gives

$$
\sum_{t=S}^{R} \frac{(1-\tau) \alpha A S^{\alpha-1} L_{t}}{(1+r)^{t-S}}=\frac{(1-\tau) A S^{\alpha} L_{S}}{1+\varepsilon}+(1-\sigma) P .
$$

The retirement equation follows using similar steps to eliminate the first term from the first-order condition:

$$
\begin{aligned}
\frac{\gamma \frac{L_{R}{ }^{1+1 / \varepsilon}}{1+1 / \varepsilon}}{(1+\rho)^{R}} & =\frac{\frac{\gamma}{1+1 / \varepsilon}}{(1+\rho)^{R}} L_{R} L_{R}^{1 / \varepsilon} \\
& =\frac{C_{R}^{-1 / \theta}}{(1+\rho)^{R}} \frac{(1-\tau) A S^{\alpha} L_{R}}{1+1 / \varepsilon}=\frac{\lambda}{(1+r)^{R}} \frac{(1-\tau) A S^{\alpha} L_{R}}{1+1 / \varepsilon} .
\end{aligned}
$$

Substitution of the last result in the first-order condition for retirement yields

$$
\frac{\eta(T-R)^{-1 / \beta}}{\lambda(1+r)^{-R}}=\frac{(1-\tau) A S^{\alpha} L_{R}}{1+\varepsilon}-\left(1-\tau_{B}\right) B .
$$

Using the implicit tax on retirement, $\varrho \equiv \frac{\left(1-\tau_{B}\right) B}{(1-\tau) W(S) L_{R}}$, we obtain

$$
\frac{\eta(T-R)^{-1 / \beta}}{\lambda(1+r)^{-R}}=\left(\frac{1}{1+\varepsilon}-\varrho\right)(1-\tau) A S^{\alpha} L_{R} .
$$

This model can be reduced into a system of three nonlinear equations- the firstorder condition for retirement, the first-order condition for education, and the household budget constraint-in three unknowns $C_{0}, S$, and $R$. For given $C_{0}$, the Euler equation for consumption fully specifies the time-path of consumption. For education level $S$ and initial consumption $C_{0}$ (and, therefore, $C_{t}$ ) we can derive the full time-path of labor supply. The education decision is a function of the retirement decision $R$ only. The retirement decision is fully determined by education $S$ and initial consumption $C_{0}$. Hence, for a given level of initial consumption $C_{0}$ the first-order conditions for education and retirement jointly determine optimal years of education and the retirement age. The level of consumption then follows from the household budget constraint. We numerically solve this set of equations subject to the Euler equations for consumption and labor supply.

Notice that we have treated the education and retirement decisions as continuous variables in these first-order conditions. The reason is that avoiding integer constraints simplifies the computations considerably. Therefore, we must adjust the available time endowment in a given year to correct for the nondiscreteness in education or retirement. For example, if an individual is enrolled for 12.2 years in education, 
the time endowment available for leisure or working in the 13th year is reduced to $1-0.2=0.8$. Similarly, when an individual retires at 50.6 years, we adjusted the available time endowment in the 51 st year to $1-0.6=0.4$. This adjustment in time endowments explains the small kinks in the labor supply paths.

\section{Elasticities}

Standard labor supply models are often cast in static frameworks, where nonlabor incomes do not change over time. This is not the case in a life-cycle setting, and this generally affects the expressions for labor supply elasticities. Only when nonlabor incomes are zero (e.g., due to a liquidity constraint), one can associate empirically measured static elasticities with the (un)compensated labor supply elasticities derived in a dynamic framework. We proceed by assuming that nonlabor income is zero (i.e., no savings or debt and no lump-sum transfers). The simulations reveal that the presence of nonlabor incomes does not affect the sizes of the elasticities much. See Blundell and MaCurdy (1999) for a more elaborate discussion on these matters.

When nonlabor income is zero, the household decides how much to work during each period. The corresponding static labor supply problem in each period is given by

$$
\max _{C_{t}, L_{t}} U\left(C_{t}\right)+V\left(1-L_{t}\right)=\frac{C_{t}^{1-1 / \theta}}{1-1 / \theta}-\gamma \frac{L_{t}^{1+1 / \varepsilon}}{1+1 / \varepsilon}, \quad \text { s.t. } \quad C_{t}=w L_{t},
$$

where $w \equiv(1-\tau) W(S)$. The first-order condition for labor supply is as before (omitting time subscripts)

$$
\frac{V^{\prime}(1-L)}{U^{\prime}(C)}=-\frac{\gamma L^{1 / \varepsilon}}{C^{-1 / \theta}}=w .
$$

Log-linearizing the first-order condition and the household budget constraint yields

$$
\frac{\mathrm{d} C}{C}+\frac{\theta}{\varepsilon} \frac{\mathrm{d} L}{L}=\theta \frac{\mathrm{d} w}{w},
$$

and

$$
\frac{\mathrm{d} C}{C}=\frac{\mathrm{d} w}{w}+\frac{\mathrm{d} L}{L} .
$$

These expressions can be solved to find the relative change in labor in terms of the relative change in the real wage. The uncompensated wage elasticity of labor supply $\epsilon^{u}$ is then given by

$$
\epsilon^{u} \equiv \frac{\mathrm{d} L / L}{\mathrm{~d} w / w}=\frac{1-1 / \theta}{1 / \theta+1 / \varepsilon} .
$$

The compensated elasticity is derived as follows. First, we totally differentiate the utility function so as to have no change in utility. Next, we use the first-order condition for labor supply to obtain

$$
\mathrm{d} C=w \mathrm{~d} L .
$$


Hence, using the household budget constraint, we find

$$
\frac{\mathrm{d} C}{C}=\frac{w}{C} \mathrm{~d} L=\frac{\mathrm{d} L}{L} .
$$

Substitution of the latter result in the linearized first-order condition and solving for the relative change in labor supply gives the compensated wage elasticity

$$
\epsilon^{c} \equiv \frac{\mathrm{d} L / L}{\mathrm{~d} w / w}=\frac{1}{1 / \theta+1 / \varepsilon} .
$$

Sensitivity analysis

This Appendix simulates the baseline model for a wide array of behavioral elasticities. Figure 2 gives the outcomes. Panel A gives the outcomes when elasticity of the human capital production function is varied between $\alpha=0.2$ and $\alpha=0.7$. A higher human capital elasticity increases the returns to education and entry in the labor market is delayed because more years are invested in initial education. As the wage rate during the working career increases, labor supply increases due to a dominant substitution effect which can be seen from the upward shift of the labor supply schedule. Also, retirement is substantially delayed when skill levels increase, as higher forgone labor earnings render earlier retirement less attractive. Clearly, skill formation is both complementary to skill utilization (labor supply) and slower skill depreciation (later retirement).

Panel B shows the simulation results in which the intertemporal elasticity of labor supply is varied from $\varepsilon=0.1$ to $\varepsilon=1.25$. A higher elasticity has a number of effects. First, the labor supply schedule rotates clockwise as individuals are more willing to substitute leisure intertemporally. Second, as the labor supply schedule rotates, average skill utilization falls because less labor is supplied during working life. Skill depreciation also increases as a higher $\varepsilon$ results in earlier retirement because forgone wages during retirement decrease when substantially less labor is supplied at the end of the working career. As skill utilization falls and skill depreciation increases, initial investment in human capital is reduced. Third, a larger $\varepsilon$ increases the wage elasticity of labor supply, and this gives stronger incentives to invest in initial education. Apparently, this effect is weaker than the negative impacts of a shorter working career and lower average labor supply.

Panel $\mathrm{C}$ gives simulations in which the intertemporal elasticity of substitution in consumption $\theta$ is changed from $\theta=0.5$ to $\theta=2.5$. This parameter has a strong impact on labor market outcomes. Indeed, compensated labor supply and retirement elasticities substantially increase as $\theta$ rises (see the Appendix). This results in higher labor supply and later retirement. Hence, the incentives for investment in human capital increase on both accounts. Second, income and wealth effects diminish when $\theta$ increases. This implies that uncompensated elasticities also increase (see the Appendix). Consequently, labor supply is boosted and retirement delayed, which results in more initial education.

Panel D shows how the outcomes are affected when the retirement elasticity is varied between $\beta=0.25$ and $\beta=1.75$. Clearly, a substantial impact of the retirement 

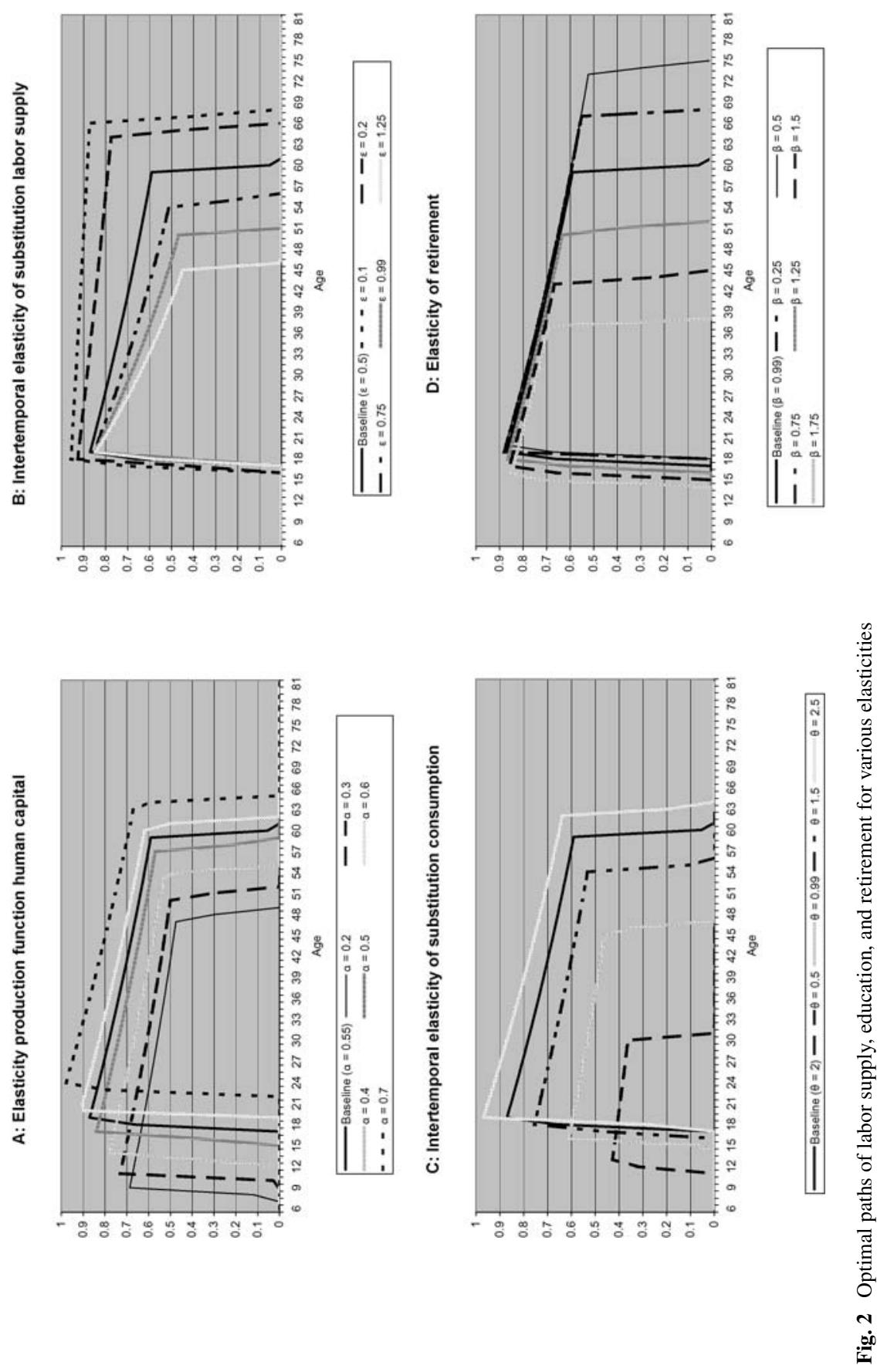
elasticity on the retirement age are found. This is the consequence of the high total (explicit and implicit) marginal tax wedge on retirement of $1-(1-\tau)(1-\varrho)=65 \%$ in the baseline scenario. Small changes in the retirement elasticity then cause large behavioral changes. As retirement ages are lower, returns to education decrease, and investments in human capital diminish. The impact is moderate mainly due to heavily discounting of more distant income streams. The impact on labor supply is very small. Earlier retirement causes a wealth effect, which boosts labor supply, whereas less education causes a substitution effect, which depresses labor supply.

Data policy parameters

\begin{tabular}{llll}
\hline & $\tau$ & $\varrho$ & $s$ \\
\hline Netherlands & 0.51 & - & 0.79 \\
Belgium & 0.66 & 0.51 & 0.87 \\
France & 0.56 & 0.61 & 0.81 \\
Germany & 0.66 & 0.09 & 0.87 \\
Portugal & 0.47 & 0.14 & 0.92 \\
Spain & 0.46 & 0.63 & 0.77 \\
Italy & 0.52 & 0.54 & 0.72 \\
Greece & 0.54 & - & 0.97 \\
Denmark & 0.49 & - & 0.97 \\
Norway & 0.51 & 0.31 & 0.97 \\
Sweden & 0.63 & 0.40 & 0.89 \\
Finland & 0.55 & 0.43 & 0.96 \\
Australia & 0.35 & 0.21 & 0.48 \\
Canada & 0.41 & 0.11 & 0.56 \\
United Kingdom & 0.41 & 0.18 & 0.70 \\
United States & 0.34 & 0.13 & 0.43 \\
\hline
\end{tabular}

Sources: Marginal total tax wedge on personal income for a single worker without children earning $100 \%$ average production wage in 2006 (OECD 2007a). Education subsidies are computed as the proportions of public expenditure on educational institutions for tertiary education in 2004 (OECD 2007b). Implicit tax rates on retirement are the averages of for a 60 -year old and 65-year old single worker with average earnings in 1999 (Duval 2004, p. 23)

\section{References}

Alesina, A. F., Glaeser, E. L., \& Sacerdote, B. (2005). Work in the US and Europe: why so different? NBER Macroeconomic Annuals, 2, 1-64.

Attanasio, O. P., \& Weber, G. (1995). Is consumption growth consistent with intertemporal optimization? Journal of Political Economy, 130(6), 1121-1157.

Auerbach, A. J., \& Kotlikoff, L. J. (1987). Dynamic fiscal policy. Cambridge: Cambridge University Press.

Becker, G. S. (1964). Human capital. A theoretical and empirical analysis with special reference to education. Chicago: NBER/University of Chicago Press (3rd ed. 1993). 
Blau, D. M. (2007). Retirement and consumption in a life cycle model (IZA Discussion Paper No. 2986) Bonn: IZA.

Bovenberg, A. L. (2006). Tax policy and labor market performance. In J. Agell \& P. B. Sørensen (Eds.), Tax policy and labor market performance. Cambridge: CESifo and MIT-Press.

Bovenberg, A. L., \& Jacobs, B. (2005). Redistribution and education subsidies are Siamese twins. Journal of Public Economics, 89, 2005-2035.

Bovenberg, A. L., \& van der Ploeg, F. (1994). Effects of the tax and benefit system on wage formation and unemployment. Unpublished manuscript, University of Amsterdam/Tilburg.

Blundell, R., \& MaCurdy, T. (1999). Labor supply: a review of alternative approaches. In O. Ashenfelter \& D. Card (Eds.), Handbook of labor economics (Vol. 3A, pp. 1559-1695). Amsterdam: Elsevier, North-Holland.

Charlot, O., \& Decreuze, B. (2007). Over-education for the rich, under-education for the poor: a search-theoretic microfoundation. Munich Personal RePEc Archive Paper No. 3624, http://mpra.ub.uni-muenchen.de/3624/.

Diamond, P. A., \& Mirrlees, J. A. (2002). Optimal taxation and the le Châtelier principle. MIT Department of Economics Working Paper Series 02-30.

De la Fuente, A., \& Doménech, R. (2006). Human capital in growth regressions: how much difference does data quality make? Journal of the European Economic Association, 4(1), 1-36.

Duval, R. (2004). Retirement behavior in OECD countries: impact of old-age pension schemes and other social transfer programmes. OECD Economic Studies, 37(2003/2), 7-50.

Evers, M., Mooij, R. A., \& van Vuuren, D. (2008). The elasticity of labor supply: a synthesis of empirical estimates. De Economist, 156, 25-43.

French, E. (2005). The effects of health, wealth, and wages on labour supply and retirement behaviour. Review of Economic Studies, 72(2), 395-427.

Gruber, J., \& Wise, D. (1999). Social security and retirement around the world. Chicago: Chicago University Press.

Gustman, A. L., \& Steinmeier, T. L. (2005). The social security early entitlement age in a structural model of retirement and wealth. Journal of Public Economics, 89, 441-463.

de Hek, P., \& van Erp, F. (2007). Analyzing labor supply of elderly people: a life-cycle approach. Mimeo. The Hague: CPB Netherlands Bureau of Economic Research.

Jacobs, B. (2005). Optimal income taxation with endogenous human capital. Journal of Public Economic Theory, 7(2), 295-315.

Jacobs, B. (2007). Real options and human capital investment. Labour Economics, 14(6), 913-925.

Lalive, R., van Ours, J. C., \& Zweimuller, J. (2006). How changes in financial incentives affect the duration of unemployment. Review of Economic Studies, 73(4), 1009-1038.

Layard, R. (2005). Happiness. Lessons from a new science. London: Penguin Books.

Layard, R., Nickell, S., \& Jackman, R. (1991). Unemployment. Oxford: Oxford University Press.

Lucas, R. E., Jr. (1990). Supply-side economics: an analytical review. Oxford Economic Papers, 42, 293316.

Mincer, J. (1974). Schooling, experience, and earnings. Cambridge: NBER; distributed by Columbia University Press, New York.

Nickell, S. (1997). Unemployment and labor market rigidities: Europe versus North America. Journal of Economic Perspectives, 11(3), 55-74.

OECD. (2004). The labor force participation of older workers: the effects of pension and early retirement schemes (Working Paper). OECD Economics Department, May 2004.

OECD. (2005a). Education at a glance. Paris: OECD.

OECD. (2005b). OECD social indicators. Paris: OECD.

OECD. (2006). OECD labor force statistics database. Paris: OECD.

OECD. (2007a). OECD tax database. Paris: OECD.

OECD. (2007b). Education at a glance. Paris: OECD.

Prescott, E. C. (2004). Why do Americans work so much more than Europeans?. Federal Reserve Bank of Minneapolis Quarterly Review, 28(1), 2-13.

Pissarides, C. A. (1998). The impact of employment tax cuts on unemployment and wages: the role of unemployment benefits and tax structure. European Economic Review, 42, 155-183.

Rust, J. (1989). A dynamic programming model of retirement behavior. In D. Wise (Ed.), The economics of aging (pp. 205-224). Chicago: University of Chicago Press.

Saez, E. (2002). Optimal income transfer programs: intensive versus extensive labor supply responses. Quarterly Journal of Economics, 117, 1039-1073. 
Saez, E., \& Gruber, J. (2003). The elasticity of taxable income: evidence and implications. Journal of Public Economics, 84, 1-32.

Sørensen, P. B. (1999). Optimal tax progressivity in imperfect labour markets. Labour Economics, 6(3), 435-452.

Stock, J. H., \& Wise, D. A. (1990). Pensions, the option value of work, and retirement. Econometrica, 58(5), 1151-1180.

Trostel, P. A. (1993). The effect of taxation on human capital. Journal of Political Economy, 101(2), 327350.

van der Klaauw, W., \& Wolpin, K. (2005). Social security and the retirement and savings behavior of low income households (PIER Working Paper 05-020). Penn Institute for Economic Research.

van der Ploeg, F. (2006). Do social policies harm employment? Second-best effects of taxes and benefits on labor markets. In J. Agell \& P. B. Sørensen (Eds.), Tax policy and labor market performance. Cambridge: CESifo and MIT-Press. 